\title{
Perancangan Game Edukasi "The Legend of Al-Khawarizmi" sebagai Alat Bantu Pembelajaran Mahasiswa Berkebutuhan Khusus
}

\author{
Iqbal Yusuf Fadillah ${ }^{1}$, Bella Hardiyana ${ }^{2}$, Rani Puspita Dhaniawaty ${ }^{3}$ \\ ${ }^{123}$ Universitas Komputer Indonesia, Indonesia \\ Email: (iqbalyusuffadillah@mahasiswa.unikom.ac.id)
}

\section{INFORMASI ARTIKEL}

Terkirim 21-Juni-2021

Revisi 16-Juli-2021

Diterima 18-Juli-2021

\section{Kata kunci:}

Game, Edukasi, Media

Pembelajaran

\begin{abstract}
ABSTRAK
Tujuan penelitian ini adalah menghasilkan game edukasi yang dapat menunjang pembelajaran bagi mahasiswa berkebutuhan khusus. Pemilihan media game diharapkan dapat menarik minat para mahasiswa berkebutuhan khusus untuk mengikuti proses belajar yang diselenggarakan oleh pihak universitas pasalnya di dalam game sendiri terdapat beberapa animasi, interaksi dan tantangan yang dapat mengubah suasana belajar menjadi menyenangkan. Game sebagai sarana pembelajaran bukanlah konsep baru, konsep ini muncul seiring dengan munculnya berbagai macam game. Dalam melakukan penelitian ini peneliti menggunakan metode Research and Development $(R \& D)$. Subjek dari penelitian ini adalah mahasiswa berkebutuhan khusus yang ada di lingkungan Prodi Sistem Informasi Universitas Komputer Indonesia (Unikom). Hingga pada akhirnya penelitian ini menghasilkan sebuah media pembelajaran berbasis game edukasi yang dijalankan pada perangkat komputer bagi mahasiswa berkebutuhan khusus yang ada di Prodi Sistem Informasi Unikom.
\end{abstract}

\section{Pendahuluan}

Pendidikan merupakan hal yang penting bagi semua manusia karena pendidikan adalah suatu usaha untuk bertumbuh menjadi lebih baik (Sumantri \& Pd, 2015). Tidak ada batasan khusus dalam menempuh pendidikan, semua orang berhak mendapatkan pendidikan. Dari penelitian yang dilakukan pada Program Studi Sistem Informasi Unikom, terdapat mahasiswa yang berkebutuhan khusus sehingga pengajar harus memiliki teknik atau metode lain yang dapat menunjang proses belajar mengajar pada mahasiswa tersebut agar mahasiswa tersebutmau dan tertarik dengan pelajaran yang diberikan (Dermawan, 2013).

Game edukasi adalah salah satu metode yang ingin diimplementasikan oleh pengajar di lingkungan Program Studi Sistem Informasi UNIKOM karena game edukasi mempunyai value tersendiri dalam berinteraksi kepada mahasiswa berkebutuhan khusus (Al Irsyadi \& Nugroho, 2015). Asas dari proses pembelajaran efektif dan efisien harus menyesuaikan dengan karakter peserta didik. Terdapat perbedaan dalam segi penyaluran materi dari pengajar ke peserta didik, baik dari segi media pembelajarannya yang akan digunakan serta durasi waktu yang diperlukan dalam proses belajar mengajar (Kurniawati, 2018).

Materi pelajaran yang akan dikemas ke dalam game pembelajaran juga harus disesuaikan dengan pengguna game, hal ini sama halnya dengan desain media atau game yang dipahami oleh pengguna yaitu mahasiswa berkebutuhan khusus (Wulandari, Susilo, \& Kuswandi, 2017). Hal ini dimaksudkan 
yaitu agar pengguna game bisa belajar secara mandiri ketika menggunakan game tersebut. Game dibuat semenarik dan semudah mungkin untuk dipahami, nantinya dalam paket game yang akan dibuat akan disertakan panduan penggunaan dari game tersebut. Penggunaan kalimat dan komposisi materi harus benar-benar diperhatikan dalam mengembangkan sebuah game pembelajaran (Susilana \& Riyana, 2008). Pemanfaatan game sebagai media pembelajaran diharapkan menjadi salah satu alternatif yang bisa digunakan dalam penyaluran materi dari dosen ke mahasiswa berkebutuhan khusus.

\section{Metode}

Metode penelitian yang digunakan kali ini oleh penulis ialah metode yang sudah tidak asing lagi. Metode yang dimana kurang lebih terdapat 4 tahapan utama di dalamnya, yaitu (1) Analisis, (2) Perancangan atau desain, (3) Pengembangan dan Penerapan dan (4) Evaluasi. Metode itu bernama Research and Development atau yang biasa kita kendal dengan $R$ and $D$. Ada beberapa faktor mengapa penulis menggunakan metode penelitian ini karena hal yang utama dari metode penelitian ini ialah menghasilkan produk tertentu dan menguji keefektifan produk tersebut (Andhini, 2017). Maka dari itu penulis berharap melalui penelitian, pengembangan, validasi produk dan uji coba produk dapat menghasilkan produk yang dapat menunjang pembelajaran secara efektif dan menyenangkan.

Penelitian ini merupakan penelitian pengembangan pendidikan atau yang biasa kita sebut Educational Research and Development yang tidak lain bertujuan untuk mengembangkan perangkat lunak berupa sumber belajar game edukatif dengan aplikasi Adobe Flash CS6 (Hanafi, 2017).

\section{Hasil Penelitian dan Pembahasan}

Secara umum, permasalahan yang dihadapi ialah bagaimana cara membuat sebuah media pembelajaran atau game yang dapat mempermudah tenaga pengajar di Prodi Sistem Informasi Unikom dalam memberikan materi perkuliahan kepada mahasiswa berkebutuhan khusus. Maka dari itu penulis memilih jenis game Role Play Gaming (RPG) guna menunjang ketertarikan pengguna yang dituju yaitu mahasiswa berkebutuhan khusus (Kurniawan, Assegaff, \& Rohaini, 2020). Tujuan utama dari game ini adalah pemain dapat belajar sambil berpetualang dan juga membuat pemain merasa tertantang dengan adanya level-level yang diberikan. Nantinya pemain akan dihadapkan dengan beberapa musuh yang dimana disetiap musuhnya terdapat pertanyaan-pertanyaan yang setema dengan mata pelajaran yang diajarkan. Untuk melanjutkan ke level berikutnya pemain harus melewati beberapa musuh dan juga pemain harus menjaga nyawa karakternya agar tidak habis apabila didapati nyawa karaker habis berarti permainan tersebut dinyatakan gagal atau kalah dan pemain harus mengulang kembali level yang dijalankannya.

Terdapat penelitian yang serupa dengan penelitian ini yaitu penelitian yang dilakukan oleh Surya Amami yang berjudul "Game Edukasi RPG Matematika" penelitian tersebut menggunakan metode kuantitatif dengan tahap analisis dan desain game. Jenis game yang diangkat sebagai media pembelajarannya serupa dengan yang peneliti rancang yaitu berjenis Role Play Gaming (RPG) dari pembuatan game tersebut dapat diambil kesimpulan bahwasannya respon pengguna terhadap Game 
Edukasi berbasis $R P G$ ialah menyenangkan, menarik dan dapat mengedukasi penggunanya(Amami Pramuditya, Noto, \& Syaefullah, 2017).

Kemudian terdapat penelitian yang serupa juga dengan yang peneliti rancang yaitu yang disusun oleh Asriyatun dengan judul "Pengembangan Game Edukatif Berbasis RPG MAKER XP Sebagai Media Pembelajaran Akutansi" penelitian ini sendiri menggunakan metode yang sama dengan penulis yaitu Research and Development dengan subjek penelitian siswa kelas XI Akutansi 1 SMKN 1 Godean. Dari penelitian ini bisa disimpulkan bahwasannya pengaruh penggunaan game edukatif berbasis $R P G$ terhadap hasil belajar siswa diukur dengan cara memberikan pre-test sebelum di uji coba dan post-test setelah di uji coba. Hasil pre-test dan post-test dianalisis peningkatannya dengan menggunakan Gain-test dengan hasil akhir bahwasannya game edukatif berbasis $R P G$ ini dapat meningkatkan hasil belajar siswa(Asriyatun \& Nugroho, 2014).

Kedua penelitian tersebut menjadi salah satu faktor mengapa penulis memilih jenis Game $R P G$ sebagai media pembelajaran yang dirancang dan dikembangkan. Berikut rincian tahapan yang digunakan penulis dalam merancang dan mengembangkan game edukasi ini berdasarkan metode penelitian yang digunakan.

1. Tahapan Analisis

Tahap analisis kebutuhan yang dilakukan pada bulan November 2020 bertujuan untuk mengetahui perlunya aplikasi pembelajaran guna menunjang pembelajaran di Program Studi Sistem Informasi Unikom. Pada tahap ini dilakukan penelitian pendahuluan yaitu observasi terhadap kondisi belajar, dosen dan mahasiswa berkebutuhan khusus yang ada di lingkungan Prodi Sistem Informasi Unikom.

\section{Tahap Desain atau Perancangan}

Pada tahap ini dilakukan berbagai diskusi dengan team terkait desain game yang akan dibuat nantinya seperti apa dan juga jenis game apa yang akan digunakan untuk penelitian kali ini. Pada tahap ini nantinya akan menghasilkan beberapa rancangan baik itu berupa desain yang meliputi mockup storyboard dan flowchart game maupun jenis game yang akan diimplementasikan nantinya. Desain yang dibuat tentunya juga akan dibuat semenarik mungkin agar mahasiswa berkebutuhan khusus tersebut tertarik untuk memainkan atau belajar menggunakan media pembelajaran berupa game ini, banyak animasi berupa karakter cartoon yang sengaja dibuat agar seolah-olah media pembelajaran ini dibuat untuk bersenang-senang layaknya game pada umumnya. Untuk perancangan storyboard dan flowchart dapat dilihat pada gambar berikut :
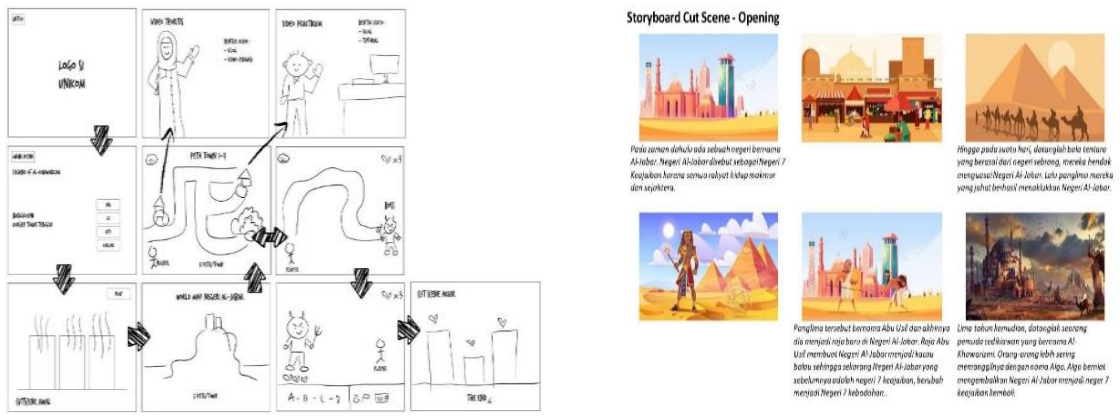

Gambar 1. Perancangan awal Storyboard 


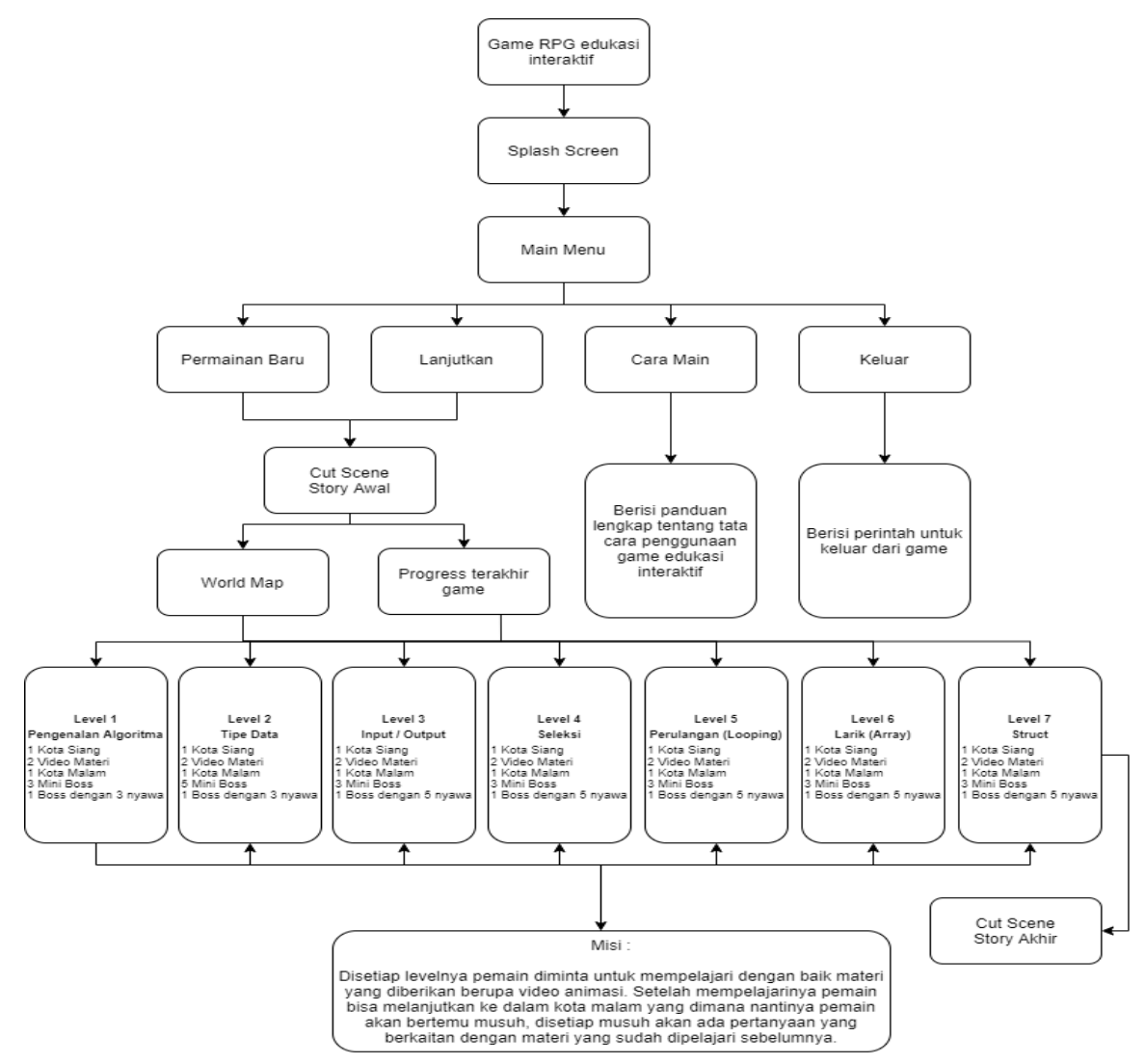

Gambar 2. Flowchart rancangan game edukasi

3. Tahap Pengembangan dan Penerapan

Pada tahap ini penulis melakukan yang biasa disebut monev atau monitoring dan evaluasi yang mengundang beberapa ahli baik itu dari bidang pendidikan maupun spesialis kejiwaan untuk meninjau langsung pengembangan dan penerapan game edukasi ini yang nantinya akan langsung diimplementasikan pada Prodi Sistem Informasi Unikom. Pada tahap ini diperoleh beberapa saran dari para ahli yang nantinya dipergunakan untuk revisi.

Tabel 1. Saran Ahli

\begin{tabular}{l|l}
\hline \multicolumn{1}{c|}{ Resoponden } & \multicolumn{1}{|c}{ Saran dan Komentrar } \\
\hline Dosen DKV Universitas & $\begin{array}{l}\text { Jenis font sebaiknya pilih yang } \\
\text { mudah dibaca oleh pemain }\end{array}$ \\
\hline Spesialis Kejiwaan & $\begin{array}{l}\text { Sebaiknya video materi } \\
\text { pembelajaran yang disajikan, } \\
\text { dicampur antara animasi dan } \\
\text { juga video asli }\end{array}$ \\
\hline
\end{tabular}


Dari masukan para ahli yang didapat, peneliti menggunakannya untuk memperbaiki kualitas media pembelajaran yang akan di rancang. Berdasarkan saran tersebut berikut perubahan atau revisi yang didapat :

Tabel 2. Revisi Media

Sebelum Revisi

\section{Evaluasi}

Pada tahap evaluasi ini dilakukan dengan menguji coba game edukasi ini kepada pengguna atau mahasiswa berkebutuhan khusus yang memang menjadi sasaran pengguna dari game edukasi ini. Uji coba ini bertujuan untuk mengetahui respond dari penilaian mahasiswa terhadap game edukasi pembelajaran interaktif yang akan dikembangkan. Uji coba dilakukan dengan memberikan hasil revisi media yang sudah direvisi berdasarkan saran dari para ahli.

\section{Pengukuran Kepuasan Pengguna Aplikasi}

Pada tahap ini dilakukan pengukuran terhadap kepuasan pengguna dengan menggunakan kuisioner. Kuisioner ini diberikan kepada 25 responden mahasiswa umum dan 5 responden mahasiswa berkebutuhan khusus sebagai pengguna game edukasi ini. Pengukuran ini diperlukan karena game edukasi yang dibangun dapat digunakan oleh mahasiswa berkebutuhan khusus maupun umum. Pengukuran ini bertujuan untuk mengetahui tingkat kepuasan penguna dalam 
beberapa indikator didalam game edukasi. Untuk mengetahui persentase dari responden, pengukuran ini menggunakan skala likert, dengan menggunakan rumus sebagai berikut :

$$
P=\frac{f}{N} \times 100 \%
$$

Keterangan :

$\mathrm{P}=$ Persentase $(\%)$ yang dicari

$\mathrm{f}=$ Jumlah responden yang memilih alternative jawaban

$\mathrm{N}=$ Jumlah keseluruhan responden

Alternative jawaban pengguna didalam kuisioner, sebagai berikut :

$1=$ Sangat Tidak Puas

$2=$ Tidak Puas

$3=$ Cukup

$4=$ Puas

5 = Sangat Puas

Pada pengukuran kepuasan pengguna ini dilihat dari 5 indikator penilaian dan 5 alternatif jawaban untuk responden (pengguna). Berikut ini merupakan hasil pengukuran kepuasan pengguna terhadap game edukasi :

Tabel 3. Hasil Pengukuran Kepuasan Pengguna (Mahasiswa Umum)

\begin{tabular}{|c|c|c|c|c|c|c|c|c|}
\hline \multirow{2}{*}{ No } & \multirow{2}{*}{ Indikator } & \multicolumn{5}{|c|}{ Responden } & \multirow{2}{*}{$\begin{array}{l}\text { Total } \\
\text { Nilai }\end{array}$} & \multirow{2}{*}{$\begin{array}{c}\text { Persen } \\
\text { tase }\end{array}$} \\
\hline & & 1 & 2 & 3 & 4 & 5 & & \\
\hline 1 & Tampilan Game Edukasi Menarik & 0 & 0 & 2 & 10 & 13 & 111 & $88,8 \%$ \\
\hline 2 & Materi Mudah Dipahami & 0 & 0 & 4 & 15 & 6 & 102 & $81,6 \%$ \\
\hline 3 & Game Edukasi Mudah Digunakan & 0 & 0 & 2 & 18 & 5 & 103 & $82,4 \%$ \\
\hline 4 & Meningkatkan Motivasi Belajar Pengguna & 0 & 0 & 4 & 16 & 5 & 101 & $80,8 \%$ \\
\hline 5 & Materi Sesuai Dengan Buku Pembelajaran & 0 & 0 & 6 & 14 & 5 & 99 & $79,2 \%$ \\
\hline \multicolumn{8}{|c|}{ Rata-Rata Persentase } & $82,56 \%$ \\
\hline
\end{tabular}

Tabel 4. Hasil Pengukuran Kepuasan Pengguna (Mahasiswa Berkebutuhan Khusus)

\begin{tabular}{|c|c|c|c|c|c|c|c|c|}
\hline \multirow{2}{*}{ No } & \multirow{2}{*}{ Indikator } & \multicolumn{5}{|c|}{ Responden } & \multirow{2}{*}{$\begin{array}{l}\text { Total } \\
\text { Nilai }\end{array}$} & \multirow{2}{*}{$\begin{array}{c}\text { Persen } \\
\text { tase }\end{array}$} \\
\hline & & 1 & 2 & 3 & 4 & 5 & & \\
\hline 1 & Tampilan Game Edukasi Menarik & 0 & 0 & 0 & 3 & 2 & 22 & $88 \%$ \\
\hline 2 & Materi Mudah Dipahami & 0 & 0 & 1 & 3 & 1 & 20 & $80 \%$ \\
\hline 3 & Game Edukasi Mudah Digunakan & 0 & 0 & 1 & 4 & 0 & 19 & $76 \%$ \\
\hline 4 & Meningkatkan Motivasi Belajar Pengguna & 0 & 0 & 0 & 3 & 2 & 22 & $88 \%$ \\
\hline 5 & Materi Sesuai Dengan Buku Pembelajaran & 0 & 0 & 2 & 3 & 0 & 18 & $72 \%$ \\
\hline \multicolumn{8}{|c|}{ Rata-Rata Persentase } & $80,8 \%$ \\
\hline
\end{tabular}


Dari hasil pengukuran kepuasan pengguna pada tabel 3, maka diperoleh persentase sebesar $82,56 \%$ menyatakan bahwa game edukasi ini mudah digunakan, memberikan materi yang menarik dan dapat meningkatkan minat belajar pengguna dalam mempelajari algoritma yang dikemas kedalam bentuk games. Sedangkan pada tabel 4 diperoleh persentase sebesar 80,8\% yang artinya sama dengan kesimpulan tabel sebelumnya. Berbeda dengan penelitian yang dilakukan oleh dua peneliti diatas. Subjek yang diteliti dari kedua peneliti tersebut ialah siswa atau pelajar pada umumnya yang tidak memiliki kebutuhan khusus, sedangkan penulis kali ini berfokus untuk merancang media pembelajaran berbasis game RPG kepada mahasiswa berkebutuhan khusus yang dimana tentunya membutuhkan beberapa penyesuaian dan fitur tambahan sebagai alat bantu dalam menggunakan game edukasi interaktif berbasis RPG ini diantaranya fitur item dan save and load. Penyesuaian dan tambahan fitur ini cukup membantu mahasiswa berkebutuhan khusus dalam memainkan game.

\section{Keterbatasan Penelitian}

Dalam melakukan penelitian ini penulis mendapati beberapa keterbatasan temuan diantaranya ialah sedikitnya subjek yang diteliti karena mahasiswa berkebutuhan khusus yang ada di lingkungan Prodi Sistem Informasi Unikom hanya terdapat 5 mahasiswa, sehingga penulis merasa bahwasannya hasil dari responden tersebut belum sepenuhnya akurat. Selain itu, game edukasi interaktif berbasis RPG ini hanya bisa dimainkan pada perangkat komputer PC saja sedangkan saat ini perangkat yang lebih sering digunakan oleh mahasiswa baik itu mahasiswa umum maupun berkebutuhan khusus ialah perangkat mobile, sehingga diharapkan penelitian ini bisa dijadikan sebagai prototype yang nantinya bisa digunakan sebagai pengembangan penelitian selanjutnya baik oleh kami maupun peneliti lain.

\section{Legalitas karya}

Selain dari diterbitkan dalam jurnal, penulis juga menerbitkan karya ini dalam bentuk Hak Cipta. Tujuannya adalah untuk mengecek originalitas karya maupun perlindungan karya selama 50 tahun kedepan. Game sudah divalidasi hak cipta (HKI) oleh Kementrian Hukum dan Hak Asasi Manusia melalui dengan jenis Permainan Video (Video Game) dengan judul "Game Edukasi 'The Legend Of Al-Khawarizmi' Sebagai Alat Bantu Pembelajaran Mahasiswa Berkebutuhan Khusus (MBK) dan Umum Versi PC" dan telah tervalidasi dengan nomor EC00202113075 yang diterbitkan pada tanggal 25 Februari 2021. 


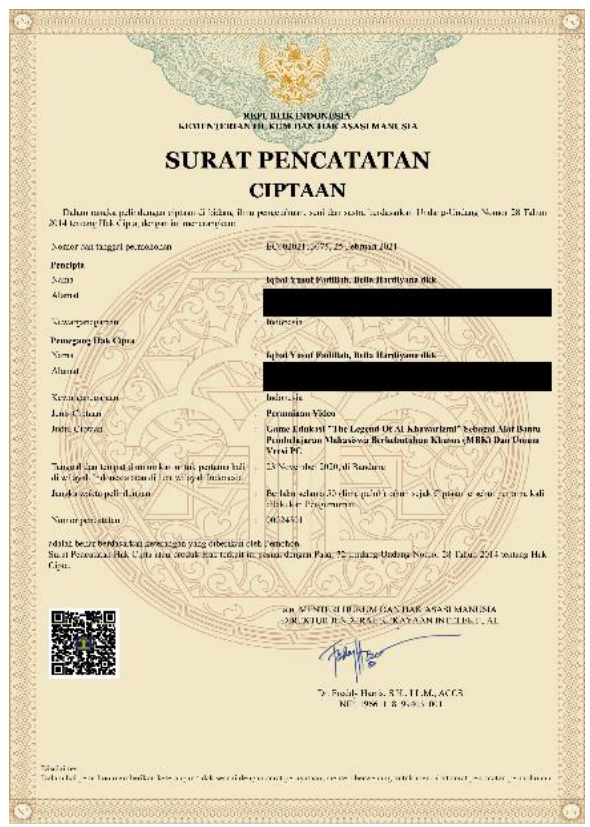

Gambar 3. Sertifikat HKI Game Edukasi "The Legend of Al-Khawarizmi”

\section{Kesimpulan}

Hasil penelitian ini berupa media pembelajaran berbasis game RPG. Media ini bertujuan untuk membantu tenaga pengajar yang ada di lingkungan Prodi Sistem Informasi Unikom dalam menyampaikan materi Algoritma baik teoritis maupun laboratorium kepada mahasiswa berkebutuhan khusus yang ada di lingkungan Prodi Sistem Informasi.

Game ini sudah dilakukan beberapa perubahan sesuai dengan masukan para ahli baik itu ahli media maupun ahli kejiwaan dan juga sudah diuji coba kepada mahasiswa umum dan mahasiswa berkebutuhan khusus. Disimpulkan berdasarkan hasil responden menunjukkan bahwa game edukasi interaktif berbasis RPG ini dapat digunakan sebagai alat bantu media pembelajaran karena mudah digunakan, memberikan materi yang menarik dan dapat meningkatkan minat belajar pengguna dalam mempelajari materi algoritma. Objek penelitian mahasiswa berkebutuhan khusus (MBK) di Prodi Sistem Informasi Unikom menjadi objek awal penelitian ini, karena hasil penelitian nantinya akan dipublish dan dapat diakses oleh siapa saja, sehingga lebih berguna bagi masyarakat dan kemajuan ilmu pengetahuan.

\section{Daftar Rujukan}

Al Irsyadi, F. Y., \& Nugroho, Y. S. (2015). Game edukasi pengenalan anggota tubuh dan pengenalan angka untuk anak berkebutuhan khusus (ABK) tunagrahita berbasis kinect. Prosiding Snatif, 1320 .

Amami Pramuditya, S., Noto, M. S., \& Syaefullah, D. (2017). Game Edukasi Rpg Matematika. Eduma: Mathematics Education Learning and Teaching, 6(1), 77. https://doi.org/10.24235/eduma.v6i1.1701

Andhini, N. F. (2017). Prosedur Pengembangan Model ADDIE. Journal of Chemical Information and 
Modeling, 53(9), 1689-1699.

Asriyatun, A., \& Nugroho, M. A. (2014). Pengembangan Game Edukatif Berbasis Rpg Maker Xp Sebagai Media Pembelajaran Akuntansi. Jurnal Pendidikan Akuntansi Indonesia, 12(1). https://doi.org/10.21831/jpai.v12i1.5165

Dermawan, O. (2013). Strategi pembelajaran bagi anak berkebutuhan khusus di slb. Psympathic: Jurnal Ilmiah Psikologi, 6(2), 886-897.

Hanafi. (2017). Konsep Penelitian R \& D Dalam Bidang Pendidikan. Saintifika Islamica: Jurnal Kajian Keislaman, 4(2), 129-150.

Kurniawan, R., Assegaff, S., \& Rohaini, E. (2020). Perancangan Game Rpg “ Mari Mengenal Provinsi Di Indonesia ” Menggunakan Unity. Jurnal Ilmiah Mahasiswa Teknik Informatika, 2(1), 13-30.

Kurniawati, I. D. (2018). Media pembelajaran berbasis multimedia interaktif untuk meningkatkan Pemahaman konsep mahasiswa. DoubleClick: Journal of Computer and Information Technology, $1(2), 68-75$.

Sumantri, M. S., \& Pd, M. S. M. (2015). Hakikat Manusia dan Pendidikan. Yogyakarta.

Susilana, R., \& Riyana, C. (2008). Media pembelajaran: hakikat, pengembangan, pemanfaatan, dan penilaian. CV. Wacana Prima.

Wulandari, R., Susilo, H., \& Kuswandi, D. (2017). Penggunaan Multimedia Interaktif Bermuatan Game Edukasi untuk Meningkatkan Aktivitas dan Hasil Belajar Siswa Sekolah Dasar. Jurnal Pendidikan: Teori, Penelitian, Dan Pengembangan, 2(8), 1024-1029. 